\title{
Research on the Functions of Government in the Development of Intravenous Industry
}

\author{
$\mathrm{Na} \mathrm{Li}^{1,}$, , Denghong $\mathrm{Chu}^{2}$ \\ School of Economics, Shanghai University, Shanghai, China

\section{Email address:} \\ Nali1535@163.com (Na Li), Chudenghong@163.com (Denghong Chu) \\ *Corresponding author
}

\section{To cite this article:}

$\mathrm{Na} \mathrm{Li}$, Denghong Chu. Research on the Functions of Government in the Development of Intravenous Industry. Science Innovation. Vol. 5, No. 4, 2017, pp. 211-215. doi: 10.11648/j.si.20170504.13

Received: March 27, 2017; Accepted: May 8, 2017; Published: May 11, 2017

\begin{abstract}
Because the venous industry has characteristics such as public goods, positive externalities, asymmetric information, the development of venous industry needs the government and the coordinated development of the market. In this paper, based on market factors contribution to the development of venous industry and processing waste yield different venous industry and venous industry can be divided into government- oriented venous industry and market-oriented venous industry, discusses the role of government in the different development model.
\end{abstract}

Keywords: Venous Industry, Market-Oriented, Government-Oriented

\section{政府参与静脉产业发展的职能研究}

\author{
李娜 ${ }^{1 *}$, 储灯红 ${ }^{2}$ \\ 经济学院, 上海大学, 上海, 中国 \\ 邮箱 \\ Nali1535@163. com（李娜）, chudenghong@163.com（储灯红）
}

摘要：由于静脉产业具有公共物品、正外部性信息不对称等特征，静脉产业的发展需要政府和市场的协同发展。本文 根据市场因素对静脉产业发展的贡献程度以及处理废品的收益不同将静脉产业分为政府主导型静脉产业和市场主导型 静脉产业，论述在不同发展模式中政府发挥的作用。

关键词：静脉产业，市场主导型，政府主导型

\section{1. 引言}

中国国家环境保护总局颁布的《静脉产业类生态工业 园区标准》将静脉产业的定义为: “静脉产业(资源再生 利用产业) 是以保障环境安全为前提, 以节约资源、保护 环境为目的, 运用先进的技术, 将生产和消费过程中产生 的废物转化为可重新利用的资源和产品, 实现各类废物的
再利用和资源化的产业, 包括废物转化为再生资源及将再 生资源加工为产品两个过程。”在中国 “垃圾围城” 的窘 境日趋严峻, 大量的垃圾没有合理的处理机制, 引起了社 会各界的关注，两会期间人大代表倡议规范垃圾分类等制 度, 这也反映出目前我国静脉产业的发展不能适应现在经 济发展的需要。因此正确认识静脉产业的发展模式以及政 府在静脉产业发展中的作用, 是推动我国静脉产业迅速成 长面临的关键课题。 


\section{2. 政府参与静脉产业发展的必要性}

静脉产业是为了解决环境和资源问题而提出的产业 发展模式, 环境和资源通常情况下被当做是公共物品, 有 外部性、信息不对称等特征, 因此静脉产业也相应的具有 公共物品性, 外部性, 信息不对称性等特征。资源在成本 和价格的形成方面不能使得市场对其进行有效配置, 造成 市场失灵。美国经济学家斯蒂格利茨把市场失灵分为两种: 一是诸如自然资源的公共物品性、外部性等因素相关联而 导致的市场失灵; 二是信息不完全、信息有偿性及不完备 的市场基础导致的市场失灵。在静脉产业的发展涉及这两 方面的市场失灵。

首先是其正外部性导致的市场失灵。对于具有正外部 性的生产商而言, 由于产出水平或收益水平将低于社会收 益的最优水平, 生产者缺乏主动性。即使在完全竞争的条 件下, 由于外部性资源配置不能达到帕累托最优, 企业等 微观经济实体由于追求自身利益最大化, 普遍会忽视社会 和环境效益。而公众由于存在着认识上的局限性和 “搭便 车” 心理, 对静脉产业的发展持被动与观望态度。因此, 我国静脉产业的发展一直处于瓶颈期。

其次是信息不完全而造成的市场失灵。社会主体受到 知识、科技的约束通常在参与静脉产业活动中存在着用不 可预见的方式对生活中的废弃物产生主观的判断, 这种判 断有很大的滞后性, 不完全性以及不确定性。随着现在宣 传教育的推广, 大部分人虽然知道废弃物具有极高的价值, 但是由于科技水平的限制, 表面的宣传并没有让人们真正 感受到废弃物带来的价值和用途, 目前人们难以完全掌握 废弃物的现实价值及潜在价值, 生产效益的不确定性生产 者并不愿意对静脉产业进行投资, 造成了废弃物资源和生 产者之间的信息不对称。二是废弃物的回收、分链和运输 都需要大量的人力物力, 而静脉产业的发展基于科学技术 的完善, 其产品具有较高的科技附加值, 需要投入较高的 研发支出, 支持废弃物的最终资源化。目前我国垃圾处理 方式基本都已集中焚烧、卫生填埋等方式为主, 垃圾分类 再利用没有形成的完整产业链, 垃圾再利用的技术不完善, 垃圾回收成本等问题使得市场基础不完备, 静脉产业发展 步履艰辛。

以上的两方面都说明，仅依靠市场机制作用，无法解 决静脉产业本身存在的失灵问题, 因此需要引入政府力量 对其进行纠正和指引。而政府干预不仅可以弥补市场失灵 带来的缺陷, 国外学者Ana[1]对于政府前瞻性的研究中认 为政府在管理方面的危机预见意识可以充当执行的催化 剂, 政府能够提供更优质的公共服务, 以满足公众的需求。

无论是以市场经济为主导的欧美国家, 还是以政府主 导型为主的东亚国家, 各国的静脉产业发展政府都给予必 要的支持。发达国家在自身发展过程中也曾出现过严重的 环境问题, 政府在静脉产业发展中投入大量精力, 通过财 政支持和法律约束等一系列措施才取得了现在的成就。日 本是目前国际社会中公认对静脉产业发展做出巨大贡献 的国家，日本政府在2000年颁布了《促进循环型社会形成 基本法》来推动循环型社会的建设。该法对国家、地方公 共团体、企业和公民都规定了相应的义务。张本越 [2]总 结了日本政府针对不同种类的废弃物制定了一系列专项
法, 提出我国发展循环经济也需要具有一定层次性和耦合 性。欧盟各国除了对垃圾的处理方面有一些宏观经济指标 的规定, 在回收、处理、再利用的各个环节上也都有限制。 Zachary [3]指出美国的《国家环境政策法》明确了国家和 各州政府对环境保护的责任, 并规定了联邦政府的相关行 为要编制环境影响报告。虽然近年来我国政府在扶持静脉 产业的发展中遇到困难, 但静脉产业发展仍然需要政府协 调和支持。

\section{3. 政府参与静脉产业发展的职能研究}

根据政府在静脉产业发展中不同的角色定位, 市场因 素对静脉产业发展的贡献程度, 以及处理废品收益不同可 将静脉产业发展模式划分为两种类型 (图1)：政府主导型 模式、市场主导型模式。政府主导型静脉产业发展模式主 要是由于静脉产业的服务具有公共物品性质, 使其不能单 纯的通过市场机制解决, 需要政府参与静脉产业的生产和 投资来主导静脉产业的发展。近年来, 国内遭雾霧袭击的 城市越来越多, 人们对环境质量更加重视, 李树 [4]认为 现在人们对环境的市场支付意愿和市场价值逐步的提高, 市场自发的对静脉产业产品和服务的需求也能够引导静 脉产业的发展。市场主导型静脉产业处于社会经济活动中, 因此其相对于政府主导型环保产业具有更高的经济效率。 但是静脉产业具有强正外部性, 企业获得的私人受益往往 小于其创造的社会收益, 导致其供给低于社会最优水平。 因此, 市场主导型静脉产业还需要政府的调节和扶持, 通 过各类公共政策降低再生资源产品的供给成本, 以实现市 场主导型静脉产业规模和结构的最优, 推进再生资源市场 的完善和成熟。

根据经济发展程度的不同, 各地在选择静脉产业发展 模式时也应该有所侧重。市场主导型静脉产业只有在一个 地区或者国家经济发展水平、社会环境意识和技术水平达 到相应的水平才具备发展的市场基础。因此, 基于我国现 阶段各地区经济发展不平衡的情景下, 静脉产业可以在长 三角、环渤海等具备大量废弃物集中产生的经济发展区域 适当发展, 而对于发展相对落后的其他地区静脉产业应主 要由政府主导展开。

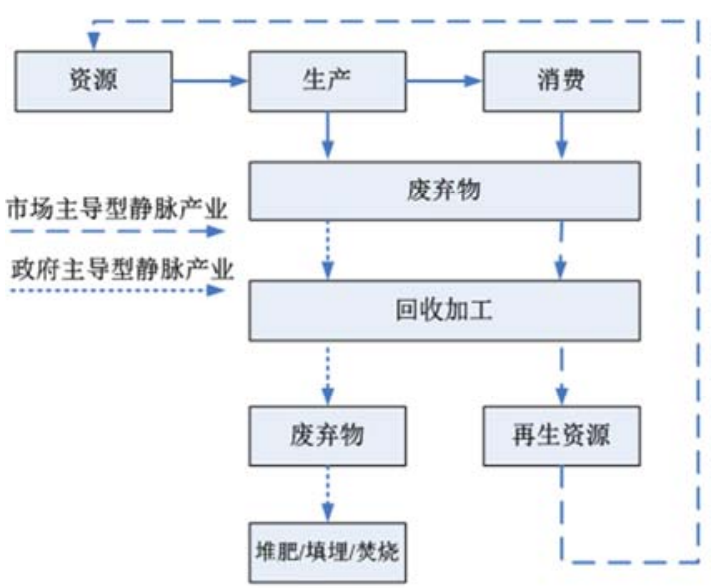

图1 市场主导型静脉产业与政府主导型静脉产业。 


\section{1. 政府主导型静脉产业中政府的作用}

政府主导型静脉产业是指: 不以盈利为目, 具有一定 非竞争性, 需要政府强制推行和财政投入的静脉产业, 即 类似于 “排放者一收运者一中间处理者一最终处理者” 市 场构造的静脉产业。例如: 危险废弃物和生活垃圾的处理。 欧文・休斯在《公共管理导论》 [5]引用安德森提出的政府 更为广泛的角色, 其中属于市场失灵的表现的情况下, 政 府最主要的职能便是提供公共物品、保护环境不受损害。

政府主导型静脉产业就是典型的公共物品, 因此政府 应逐步增加财政投入，改善政府对此类静脉产业的投入方 式并完善财政支出政策, 增强公共资金的使用效益, 并要 提供强制的法律约束和综合的技术保障。充当生产者、提 供者和安排者的角色。因此政府在政府主导型静脉产业中 的作用归纳为：建设规划，法规保障，技术支持。

\section{1. 1. 建设规划}

建设规划即政府直接拨款及投资兴建部分静脉产业 项目, 并且解决静脉产业建设过程中的问题, 为静脉产业 的发展提供长远的规划。政府作为静脉产业的提供者, 虽 然不直接产于生产环节但需要在资金方面落实到生产环 节的各个方面。目前我国的科学技术还未达到废物处理目 标, 尤其是对于无再利用价值的生活垃圾方面的处理, 我 国现已建设完成的综合类静脉产业园区 (以生活垃圾处理 为核心) 数量距离完全处理大量的生活垃圾实现 “零填埋” 的目标还很远。近年来, 城市生活垃圾的清运量逐年增长, 但根据2015年中国统计年鉴数据显示, 我国垃圾焚烧两仅 占无害化垃圾处理量的 $32.5 \%$, 大部分垃圾选择卫生填埋 的处理方式, 在中国西部地区大部分省市的垃圾处理仅做 简单的填埋, 还未建立垃圾焚烧站。而目前的综合性静脉 产业园区的发展和运营也出现运营效率低等问题。这就需 要政府大力地投入资金和人力解决相关问题。

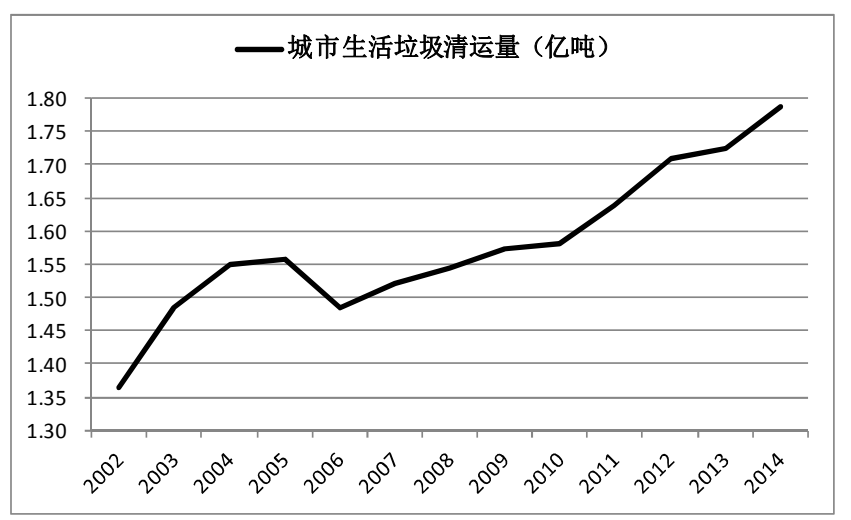

图2 城市生活垃圾清运量。

\section{1.2. 法规保障}

法规保障不仅要求政府在废弃物回收方面约束废物 生产者行为, 而是通过法律服务为生产者、消费者、中央 政府和地方政府提供通力合作的一个系统, 使每个社会主 体合理承担自己该履行的义务和责任, 更高效的实现废物 的最终处理。对于危险废弃物的处理, 政府需利用法律措 施强制统一销毁危险废弃物。对于一般废弃物而言, 政府
法规制定者需要从企业、政府和消费者等角度出发, 颁布 各类法规条例建立健全回收体系。目前国家关于静脉产业 的法律文件和政策制度有《固体废弃物污染环境防治法》、 《资源综合利用目录》以及《中华人民共和国循环经济促 进法》, 其中都有涉及关于废弃物排放和处理的相关办法 和措施, 但是这些办法对生产者、回收者以及消费者的约 束力度不够, 对于细分的各类垃圾处理措施没有明确的标 准和规定, 使得消费者和回收者责任不明确, 进而导致一 些静脉产业园出现 “吃不饱” 的情况。董芳青等 [6]在对 天津子牙静脉类产业园区调查发现, 我国静脉产业回收体 系不健全，法律法规不完善导致静脉产业的原材料供应不 足, 影响静脉产业园的运行效率。

\subsection{3. 技术支持}

废弃物在静脉产业中能够得到最终处理的一个关键 因素就是与静脉产业发展有关的最终处理处置技术。日本 政府长期以来推动政府、学校、科研机构、企业及人民群 众紧密合作, 以达到 “政府主导、学术支持、公众参与、 企业经营” 的官一学一产一民相互协作的目的, 从而推进 循环经济发展。目前世界上最先进的节能降耗环保技术基 本都由日本研发。因此政府在主导静脉产业发展的过程中 需要联合高校、科学研究界等各方力量, 支持静脉产业发 展, 实现废弃物零排放的目标。

\section{2. 市场主导型静脉产业中政府的作用}

市场主导型静脉产业是指: 除政府主导型静脉产业外, 以盈利为目的, 以市场为导向的静脉产业, 即类似于国内 学者聂永有 [7]提出的 “排放者一收运者一再生处理者一 再生资源批发业者一再生资源利用产业者” 市场构造的静 脉产业, 例如: 再生资源产业。市场主导型模式中, 静脉 产业的发展是以市场需求引导为主, 要充分发挥市场经济 的资源配置作用, 利用市场机制构建合理的再生资源价格 体系, 推进再生资源的利用, 避免外部性产生。并辅之以 必要的政府政策的扶持和引导。这种发展模式中, 政府发 挥的作用归纳为: 政策支持、创造市场、监督维护、推动 技术创新。

\subsection{1. 政策支持}

市场主导型静脉产业既有公益性, 也有商业利益性, 但由于废旧产品和废弃物回收成本较高, 再生资源回收的 效益不能完全转化为企业的经济效益, 企业难以实现盈利 的目标。因此要启动再生资源回收利用市场, 必须依靠政 府经济手段的调控, 通过财政政策, 引入企业并帮助企业 提供健全的回收网络。

日本在《推进循环型社会形成基本法》中规定，为促 进循环型社会的建设, 政府必须采取必要的财政措施给予 相应的支持。在可再生资源方面, 日本政府对处置废弃物、 回收设备的制造商给予相当于其生产、研发费用的 $50 \%$ 的 财政补贴。日本政府在资源循环利用技术开发上给予财政 补贴和税收优惠。由此可见, 如果没有国家提供财政支持, 日本现有的废弃物回收体系难以独立维持的。落户于美国 康奈狄克州的再生资源加工利用企业不仅可获得低利率 
风险小额贷款，还能享受减免州级企业所得税、设备销售 税及财产税的福利。各国学者都做了大量关于政策扶持对 静脉产业的激励作用的研究。Bruvo11 [8]运用一般均衡模 型分析了政府对原生材料采取较重的税收或者较少的劳 动报酬有助于相对要素价格的变化, 且不会增加总成本, 政策的倾斜能跟好的实现资源循环再利用。而韩庆华等 [9] 分析我国财政政策对循环经济发展的影响, 回归分析显示 财政政策对 “三废” 综合利用激励作用明显。综合研究和 实证研究都表明, 财政政策作为废弃物回收利用的的重要 的政府激励制度之一, 政府给予适当的政策补贴保证企业 合理的经济利益，并且提供一定的科技投入，是激励企业 扩大生产规模的关键因素, 也使再生资源企业达到社会最 优的供给水平。

\subsection{2. 创造市场}

创造市场就是政府为市场型静脉产业创造良好的消 费市场, 确保再制造产品有销售畅通, 激发生产者的主动 性, 完善市场结构。由于静脉产业的发展依靠废弃物处理 技术的进步, 属于技术密集型产业, 故其生产成本一般情 况下高于由自然资源直接加工的产品, 在同等产品竞争市 场上处于劣势地位, 仅仅通过价格杜杆的作用, 难以达到 再生资源产品畅销的目的。因此就需要政府确保再生产品 的需求, 并且引导消费者对再生资源产品的需求。美国政 府为激励公众参与回收和消费环保产品, 2004年到2006 年间每年对各州政府拨款 30 多亿美元, 推动旧家电的回收 并鼓励公众购买节能家电产品。日本政府2000年颁布了 《绿色采购法》, 明确规定了政府机关部门要优先购买环 保型产品。2007年初, 我国财政部和环保总局联合发布了 我国第一份政府采购 “绿色清单”。从2007年1月1日起, 国家机关、事业单位和团体组织在用政府财政资金进行采 购时率先实行 “绿色采购”。在 2015 年最新公布的《第十 八期环境标志产品政府采购清单》中明确注明政府统一使 用再生复印纸和再生鼓粉盒。政府对环保产品的采购金额 从2008年171亿元到2015年达到1360亿元, 复合增长率达 到 $87 \%$ ，表明政府在绿色采购方面的决心。

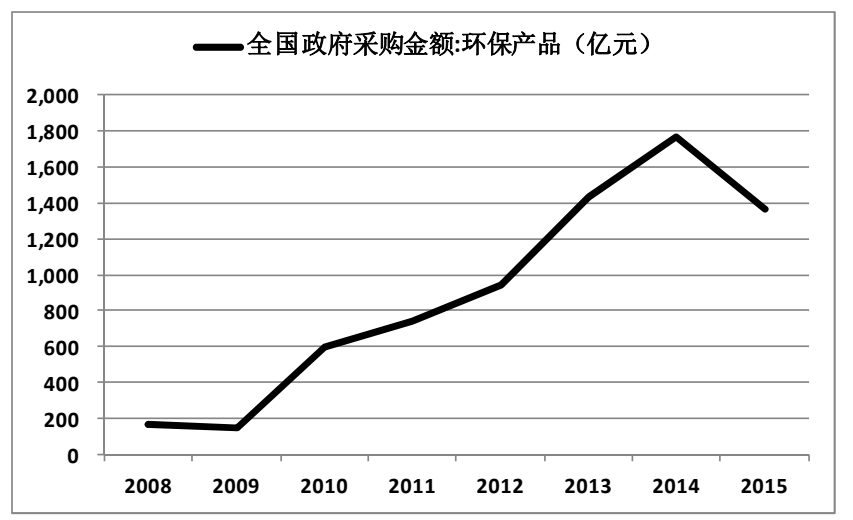

图3 政府环保产品采购金额。

\subsection{3. 监督维护}

监督维护即政府需要在鼓励企业提高资源利用率以 及通过再回收渠道减少垃圾排放的同时, 也需要维护的拥
有正规回收厂商的正常运营回收渠道, 帮助企业整顿目前 市场上杂乱的回收秩序, 并且监管垃圾的整个回收流程, 避免二次污染。石秀萍等 [10]总结目前我国静脉产业发展 中存在以下问题: 配套制度不完善、资源利用率低、技术 和管理能力弱、二次污染严重。在中国, 废物回收一般都 是由社会无业人员承包, 而废品收购点大多是一些没有正 规经营手续垃圾场, 不仅没有进行分类处理还造成了垃圾 的二次污染。而这类企业也是一些技术含量不高, 生产设 备简陃的小作坊, 而大部分废旧物资集中到这类小企业, 具有废旧资源处理能力的企业没有足够的废旧资源造成 了资源浪费。

在资源回收方面Chi Xinwen[11] 也认为在中国等发 展中国家的大部分电子废弃物回收方式都是非正式的是 因为再制造企业的供给不足，而政府简单的禁止这种非正 式的回收方式不是有效的解决方案, 政府应该制定相应的 鼓励措施减少不当的回收活动, 让电子垃圾流入正规部门。

\section{2. 4. 推动技术创新}

政府推出的环境政策有直接的强制性的法律法规，对 污染排放着制定排放标准和技术处理标准等，也有间接地 非强制性措施, 包括收取环境税费, 发放排污交易许可证, 还有宣传教育等工作。根据学者研究表明, 政府的非强制 性措施对于企业研发投入具有间接激励作用。余伟 [12] 利用我国省级面板数据研究了我国环境政策工具对技术 创新方面的影响。研究表明仅全国来看 “软手段”（宣传 教育、劝说鼓励等手段) 对企业R\&D投入有显著地促进作 用。但是分区而言, 经济手段 (税收等) 对我国内陆地区 企业的R\&D投入具有明显地促进作用，而 “软手段” 对我 国东部地区企业的R\&D投入具有促进作用。

李凡 [13] 通过研究企业对太阳能技术的改进的案例, 对政策工具选择的研究方面也提出: 需求拉动（税收、标 准管制、交易许可等形式) 和技术推动（主要形式为直接 投入公共研发资金) 政策工具对提升太阳能技术创新能力 均有推动作用, 在更为细分情况下, 需求拉动工具中的税 收等价格机制工具比制定标准或设置配额等数量型工具 的促进作用更为明显; 对区域分组后发现：技术推动工具 对资源不丰富地区的太阳能技术创新能力提高影响跟大, 而在资源丰富地区, 需求拉动工具中的价格型工具促进作 用更为显著。

\section{4. 结论}

在政府主导型静脉产业的发展过程中, 政府需要在大 局上进行规划建设，在法律法规等基础上限制消费者、企 业的排放回收再处理等行为, 并通过政府等社会资源, 促 成 “官一学一产一民” 的紧密协作, 为政府主导型静脉产 业的发展提供良好的发展基础。

在市场主导型静脉产业发展过程中, 政府通过法律途 径对市场准入、市场竞争和市场纠纷处理等方面进行限制, 保护市场主导型静脉产业的交易和竞争秩序。政府根据经 济发展程度不同或自然资源拥有量不同对地域分类, 实行 不同的经济手段, 为市场主导型静脉产业创造市场机会并 间接提升企业的研发力度。例如, 德国政府为参与废弃物 
的回收和利用的相关企业设立专门的机构, 监督企业按照 循环经济发展的相关规定进行生产经营。企业需要具备回 收处理废弃物的能力和水平并得到相关机构证明, 才能进 入该行业进行相应的生产经营活动。同时政府也需要对市 场主导型静脉产业的经营资质，经营范围和产品标准等进 行严格的监督和审查。规范的监督和维护为静脉产业的健 康和可持续发展创造了适宜的市场环境, 提高资源配置的 效率。

\section{参考文献}

[1] Ana Yetano. Managing Performance at Local Government LeveI : The Cases of the City of Brisbane and the City of Melbourne. The Australian Journal of Public Administration, 2009, 68(2), 167-181.

[2] 张本越. 日本静脉产业对策的层次性与耦合性 $[\mathrm{J}]$. 社会科 学家, 2016, (05) :55-59。

[3] Zachary A. Smith. Environmental Policy Paradox [M]. Longman, 2009

[4] 李树. 环保产业发展中 “政府与市场” 合作模式研究 [J]. 经 济纵横, 2013, (09) : 103-106。

[5] (澳) 欧文・E. 休斯 (Owen E. Hughes) 著; 张成福等译. 公 共管理导论第3版. 北京: 中国人民大学出版社, 2007.03。
［6］董芳青, 楚春礼, 周恋秋, 鞠美庭, 邵超峰. 我国静脉产 业园原材料来源调查与国际经验借鉴 $[\mathrm{J}]$. 生态经济, 2016, (09) : 95-99.

[7] 聂永有. 循环经济条件下的静脉产业发展探索 $[\mathrm{J}]$. 南方经 济, 2005, (12) : 95-97。

[8] Bruvoll Annegete. Taxing virgin materials: an approach to waste Problems $[\mathrm{J}]$. Resoures Conservation and Recycling, 1998, 22(1) : 15-29

［9］韩庆华，王晓红. 促进经济循环发展的财政政策实证研究 [J]. 经济学动态, 2008, 09:64-68。

[10］石秀萍, 杨强. “静脉产业” 的发展中存在的问题及对策 建议 [A]. 中国环境科学学会. 2013中国环境科学学会学术 年会论文集 (第三卷) $[C]$. 中国环境科学学会: , 2013:3。

[11] Chi Xinwen, Streicher-Porte Martin, Wang Mark Y L, Reuter Markus A. Informal electronic waste recycling: a sector review with special focus on China. [J]. Waste Management, 2010, 314.

[12] 余伟，陈强，陈华，不同环境政策工具对技术创新的影响 分析一一基于 2004-2011年我国省级面板数据的实证研究 [J]。管理评论, 2016, (01):53-61。

[13] 李凡, 李娜, 许听. 基于政策工具的可再生能源技术创新 能力影响因素研究 $[\mathrm{J}]$. 科学学与科学技术管理, 2016, (10):3-13。 